\title{
Lobular Neoplasia Type A
}

National Cancer Institute

\section{Source}

National Cancer Institute. Lobular Neoplasia Type A. NCI Thesaurus. Code C83170.

Lobular neoplasia of the breast characterized by the presence of neoplastic cells with uniform nuclei. 